Article

\title{
An Aristotelian Interpretation of Bojo Jinul and an Enhanced Moral Grounding
}

\author{
Song-Chong Lee \\ Religious Studies and Philosophy, University of Findlay, Findlay, OH 45840, USA; lee@findlay.edu
}

Received: 17 March 2020; Accepted: 13 April 2020; Published: 16 April 2020

check for updates

\begin{abstract}
This paper explores the eclecticism of Bojo Jinul (1158-1210 CE), who is arguably the most influential historic figure in establishing and developing the Buddhist monastic institution of Korea. As a great harmonizer of the conflicting Buddhist trends in the late Goryeo period, Jinul not only shaped the foundation of the traditional monastic discipline balanced between theory and practice but also made Korean Buddhist thoughts known to a larger part of East Asia. I revisit the eclecticism of Bojo Jinul on harmonizing the two conflicting understandings of enlightenment represented by Seon (Cha'n) and Gyo (Hwaeom study) schools: the former stressing sudden enlightenment by sitting mediation and oral transmission of dharma and the latter stressing gradual cultivation by the formal training of textual and doctrinal understanding specifically on the Hwaeom Sutra. Utilizing the metaphysics of Aristotle, I confirm the logical validity of his eclecticism and address some of its moral implications.
\end{abstract}

Keywords: Korean Buddhism; Jinul; sudden enlightenment; gradual cultivation; Korean Seon; Zen; potentiality and actuality; Aristotelian metaphysics

\section{Introduction}

This paper explores the eclecticism of Bojo Jinul (1158-1210 CE), who is arguably the most influential historic figure in establishing and developing the Buddhist monastic institution of Korea. As a great harmonizer of the conflicting Buddhist trends in the late Goryeo period, ${ }^{1}$ Jinul not only shaped the foundation of the traditional monastic discipline balanced between theory and practice ${ }^{2}$ but also made Korean Buddhist thoughts known to a larger part of East Asia. Some of his writings were passed to China through the Ming collection of Buddhist Tripitaka and also shared with the Japanese Buddhist community. ${ }^{3}$ Differing from other contemporary Seon thinkers, Jinul was very systematic in harmonizing spiritual practices and the Hwaeom philosophy. ${ }^{4}$ In this paper, I utilize Aristotle's ontology to explain Jinul's eclecticism, harmonizing the two conflicting understandings of enlightenment represented by Seon (Cha'n) and Gyo (Hwaeom study) schools: the former stressing sudden enlightenment by sitting mediation and oral transmission of dharma and the latter stressing gradual cultivation by the formal training of textual and doctrinal understanding specifically on the Hwaeom Sutra. These two approaches not only represent the fractious climate of the Buddhist community during the Goryeo period but also reflect a larger enduring controversy on the moral grounding of spiritual enlightenment in mundane reality.

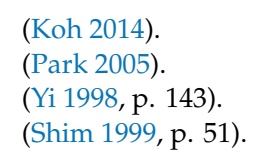


Although coming out of and following the tradition of the Nine Mountain Schools of Korean Seon, ${ }^{5}$ Jinul recognized the positive value and function of the Hwaeom study school, which most of his people, Seon monks, would challenge for their theoretical validity and methodological efficacy. According to Jinul, both Seon and Gyo schools were suffering apologetic flaws, which are nuanced by Keel's characterization of Gyo as "expansion" and Seon as "concision". ${ }^{6}$ If these two practices lose their original spirits and become extreme, they could subject to unexpected consequences. While the former can suffer from self-aggrandizement, the latter can suffer from self-abasement. ${ }^{7}$ In contrast to other Seon thinkers, Jinul tried to find a balanced theoretical framework, which could embrace the wide-ranging paradigmatic characteristics of these conflicting schools. In particular, he tried to clarify what it means to experience sudden enlightenment in the process of spiritual and moral cultivation in the form of the Bodhisattva vow. He believed that the Gyo approach is indispensable to translate the metaphysical state of Buddhahood into the spiritual and moral language for the physical reality. To clearly draw moral implications of Jinul's syncretism and eclecticism, I utilize Aristotle's argument of being; argument of potentiality and actuality. This Aristotelian interpretation shows how the idea of the Buddhahood attained from sudden enlightenment can be logically justified and sustained in conjunction with the necessity of spiritual cultivation. I conclude that when interpreted by Aristotle's notion of actuality, Jinul's syncretism offers a firmer theoretical grounding, particularly for moral cultivation. To reflect the conference theme of Religious Conflict and Coexistence, my conclusion will include a brief discussion of some moral implications of Jinul's eclecticism.

\section{Focus of Discussion}

Prior to the main discussion, it seems worth noting the focus and scope of my analysis with Aristotle's metaphysics. Jinul's syncretic and eclectic effort to balance between sudden awakening and gradual cultivation is not his own invention. There had already been serious conversations and debates in Chinese Buddhist communities on how to harmonize the different paths of enlightenment. Many thinkers from various sectarian communities were trying to come up with a unified system of thought and practice. Good examples include Chih-i (538-597) of the T'ien T'ai; Fa-tsang (643-712) and Ch'eng-kuan (738-840) of the Hua-yen; and Tsung-mi (780-841) and Yen-shou (904-975) of the Cha'n. However, as Buswell notes, most of them, particularly thinkers of Cha'n Buddhism, failed to "go beyond the recognition of correspondences to an explicit effort to merge the two sects either doctrinally and practically". 8 The arguments from the Korean Buddhist community were neither persuasive nor productive. For instance, according to Jinul's assessment, Toui's inordinate emphasis on emptiness had made the Hwaeom method of gradual cultivation pejorative and useless. Muyeom's emphasis on the tradition of the Patriarchs had failed to explain the deep soteriological dimension of Samadhi. ${ }^{9}$ He believed that sudden awakening and gradual cultivation are not two different spiritual experiences but a single state of enlightenment, which is fully revealed or realized through the process.

Therefore, my discussion is aimed at giving new light to Jinul's argument for the unity of these seemingly separate events. To better analyze Jinul's argument structure and points, I invite Aristotle's ontological framework of potentiality and actuality. Although it seems unfit, from the outset, to utilize the concept of actualization for the notion of Buddhahood, since the Buddha nature pursued by Seon practitioners is beyond any typology of existence, I believe that Aristotle's point on the change/transformation rendered and guided by and within the form of a phenomenal experience is

\footnotetext{
(Mu 1987, p. 87).

(Keel 2012, p. 63).

By self-aggrandizement, I mean the spiritual arrogance due to the inordinate confidence in the person's internal experience, which has yet to reveal its practical impact. By self-abasement, I mean the person's low self-esteem caused by the absence of his or her inner, divine potential.

8 (Chinul and Buswell 1983, p. 37).

9 (Shim 1999, p. 15).
} 
still meaningful in explaining the concurrence and coexistence of the experience of awakening, which is the complete state of Buddhahood, and the necessity of cultivation, which demands spiritual and moral practices. To focus my discussion specifically on Jinul's eclecticism, I will use, as the primary text, his Secrets on Cultivating the Mind, which provides details on the relationship between sudden awakening and gradual cultivation. For the interpretative framework to help explain the unity of being between the Buddha nature and the monk on spiritual cultivation, I will utilize Aristotle's discussion of potentiality and actuality in the Book XI of Metaphysics.

My utilization of Aristotle's hylomorphism for Jinul's eclecticism may be retrospective of Keel Hee-Sung's Salvation According to the Korean Zen Master Chinul and Karl Barth, which was published in 1989 by Buddhist-Christian Studies. ${ }^{10}$ Keel used the Barthian soteriology harmonizing justification/faith and sanctification to defend the theoretical coherence of Jinul's eclecticism. Similarly, my use of Aristotelian ontology is intended to respond to the major question about how the final, ultimate stage of spirituality can both precede and necessitate the seeker's cultivation. Just as Keel made justification/faith and sanctification parallel with sudden enlightenment and gradual cultivation, respectively, I will juxtapose Aristotle's ontology of potentiality and actuality with Jinul's soteriology of Buddhahood. My argument is that Jinul's eclecticism is not self-contradictory. Neither of the spiritual experiences, sudden awakening and gradual cultivation, would be sacrificed by his syncretic attempt particularly when the Buddha nature (the Ultimate Truth) is viewed as actuality, the awakened monk as potentiality, and the cultivation process as actualization of Aristotle's metaphysics.

There is an important point that I need to clarify before proceeding with my discussion about Aristotle's hylomorphism. Some may feel uncomfortable about bringing the conversation on Buddha nature into a theory of being because according to the universal belief of Seon Buddhism, the Buddha is neither being nor non-being; at the same time, it can be being and non-being. Since the definition is elusive, Aristotle's logical analysis of being seems inapplicable. Therefore, my use of being should be distinguished from the general qualifications discussed in both Physics and Metaphysics. Although it is not right to conceptualize Buddha and claim that there is a specific way and form in which it exists, all Buddhists, including Seon practitioners, would agree that Buddha is real. It is a being not in a physically and conceptually fixed sense but as that which manifests and makes itself known to us. Even if it is impossible to put into words how Buddha exists, the fact that it exists and interacts with the world in the conventional sense and that there is substantial change, progress, or transformation in the life of the awakened monk is undeniable. In particular, considering the Mahayana teaching of fifty-two stages of Bodhisattva, the Buddhist notion of ultimate reality is not the same as Aristotle's Supreme Reason and God. Thus, my utilization of Aristotle's hylomorphism is limited to illuminating the logical basis of the ontological transition of the awakened monk from one stage to another, which presupposes a variety of changes such as quantity, quality, power, and maturity.

\section{Buddha Nature as Actuality}

Aristotle's Metaphysics discusses how being can be perceived, understood, and analyzed logically. Book XI covers the relationship between being X potentially and being X actually. While the potentiality of a thing is the power and conditions to become what it is ontologically destined to be, actuality is the motion, change or activity that represents an exercise or fulfillment of a possibility. ${ }^{11}$ It is also the telos toward which being is transforming. When Aristotle's actuality and potentiality are compared with sudden awakening and gradual cultivation, respectively, Jinul's claim that the Buddhahood precedes the monk's cultivation and that they should be in unity seems more plausible. In particular, Aristotle's notion of actuality (Section 3) supports the first two of Jinul's three major arguments: (a) awakening to the Truth or the Buddha nature should happen before cultivation in the ordinary sense of time;

10 (Keel 1989).

11 (Durrant 1993, p. 206). 
(b) gradual cultivation necessitates the sudden, complete awakening as the power and telos for the full realization of the Buddha; and (c) both spiritual events should be in unity in the ultimate sense of time. Sections 4 and 5 on potentiality and actualization in this paper will provide a logical support for Jinul's second and third arguments respectively.

Actuality precedes potentiality. ${ }^{12}$ Aristotle says, "Actuality is prior to all potentiality of this sort both in account and in substance; and in time in one way it is and in another way it is not" ${ }^{\prime 13}$ This means that actuality of a being as form is already in place before its potentiality is activated. The idea, capacity, and ontological direction are inherent within the being. Our sense experience of the being is simply the outcome of the actuality and form of the being. Aristotle articulates the priority of actuality by saying:

So that it is evident that the things which are potentially are discovered when they are drawn out into actuality; the explanation is that thinking is the actuality; so that the potentiality is from actuality, and because of this they know by making (for the individual actuality is posterior in coming to be). ${ }^{14}$

As mentioned above, Aristotle explains the precedence of actuality in three different ways: (a) Actuality precedes potentiality in account. He explains, "I mean by able-to-build what is capable of building and by able-to-see what is capable of seeing and by visible what is capable of being seen". ${ }^{15}$ The potential of each example presumes the capacity that it intends. Aristotle continues, "It is necessary for the account and the knowledge of the one to precede the knowledge of the other". ${ }^{16}$ (b) Actuality is also prior in time. Beings that are already active but still potential may look prior because the final outcome comes from it in order. However, Aristotle notes the very source of change. It is actuality. He says:

It is always the case that from what is potentially what is actually comes to be, by means of what is actually, for example, man from man, musician by means of musician, in each case something bringing about change first; and what brings about change already is actually. ${ }^{17}$

(c) Finally, actuality precedes potentiality in being or substance. Since the form as actuality has the state of being, toward which the maximized capacity and quality of the matter as potentiality are set, it exists first.

"Things posterior in coming to be are prior in form and in substance (for example, adult to boy and man to seed; for the one already has the form, the other does not), and because everything that comes to be proceeds to an origin and an end (for that for the sake of which is an origin, and the coming to be is for the sake of the end), and the actuality is an end, and the potentiality is acquired for the sake of this". ${ }^{18}$

This hylomorphism can help make Jinul's argument plausible for the harmony between sudden awakening, which is the methodological foundation of his Seon tradition, and gradual cultivation, and particularly for his points of the priority of sudden awakening and the unity of those experiences. According to Jinul, if using Aristotelian language, Buddha is the form. To be more specific, it is the absolute form or God, which does not necessitate any potentiality to be real. However, since this paper focuses on the theme of the spiritual transformation and fulfillment of being rather than

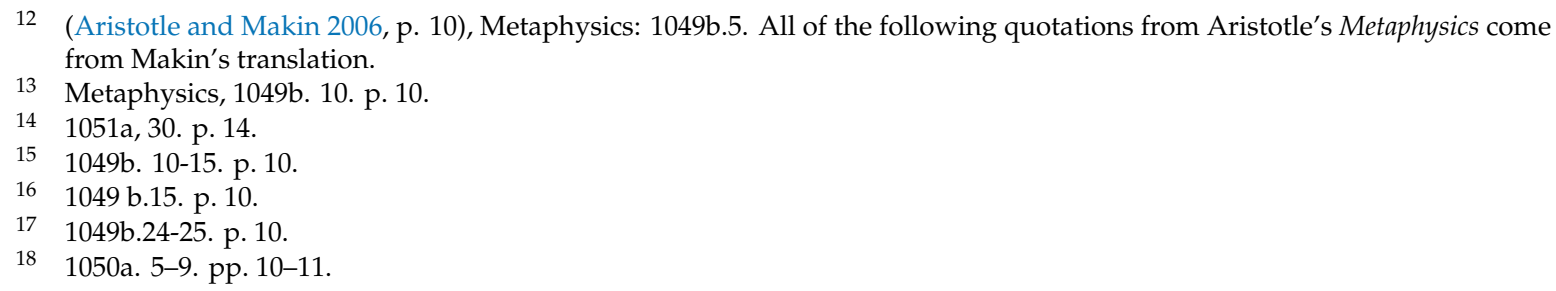


the philosophical discussion of God, it does not deal with the question of whether Jinul's notion of Buddhahood can be compatible with Aristotle's notion of God. They are, as a matter of fact, different. While Aristotle's God as unmoved mover and uncaused cause is the God derived from the logical conclusion under the law of physics, Jinul's notion of Buddha demands a different kind of understanding and explanation able to embrace any type of polarity, including form and matter, substance and accidents, and personal and impersonal attributes. However, Aristotle's hylomorphism is still relevant to Jinul's eclecticism because the Buddhist notion of awakening and cultivation necessitates a change or transformation from one state of consciousness to another, whether those experiences happen concurrently or in a consecutive order.

The notion of awakening and enlightenment in Jinul's Secrets on Cultivating the Mind (SCM hereafter) shares common characteristics with Aristotle's actuality. It is the ontological state, which every Seon practitioner as a being pursues to attain, and the ultimate nature and telos of all beings. Although the telos of everything biological would be death and extinction in the conventional dimension, it is the highest state of being in the ultimate dimension, whose existential reality is substantial but cannot be settled in a conceptual framework. The actuality that all human beings, including Buddhist adepts and ordinary people, are supposed to realize is the Buddha nature. It is the ultimate stage of our ontological qualities and our true, completed identity. In Jinul's language, the actuality as being is "the self-nature" and "the mind of void and calm, numinous awareness". ${ }^{19}$ It is the highest ontological state into which the whole being of the person including the body and the mind needs to be dissolved. As Jinul notes, this actuality has a variety of names, depending on the scripture: the mind-ground in the Bodhisattva Síla Sūtra, bodhi or nirvana in the Prajñāpāramitā Sutras, dharmadhatu in the Avatamsaka Sutra, Tathāgata in the Diamond Sutra, suchness in the Golden Light Sutra, the dharma-body in the Pure Name Sutra, Tathāgatagarbha in the Śrīmālādevī Siṃhanāda Sūtra Sutra, etc. ${ }^{20}$ Like the fully grown and functioning adult as the actuality of an infant in Aristotle's examples, the Buddhahood as the self-nature is inherent in every being. In other words, our own natures are "the true dharma". ${ }^{21}$ It is our mind where Buddhahood can be attained. ${ }^{22}$ Like the form and actuality, the Buddhahood that we inhere is "originally whole and complete in itself". ${ }^{23}$ Jinul says:

Rather, it stresses that everyone is originally a Buddha, that everyone possesses the impeccable self-nature, and that the sublime essence of nirvana is complete in everyone. There is no need to search elsewhere; since time immemorial, it has been innate in everyone. ${ }^{24}$

The problem is that we have the false beliefs that it is the dimension of the body that defines our identity and determines our capability and that salvation is outside of our beings. Jinul articulates the problem that prevents us from seeing the actuality:

It (Buddha Mind) is not outside the body. The physical body is a phantom, for it is subject to birth and death; the true mind is like space, for it neither ends nor changes. Therefore it is said, "These hundred bones will crumble and return to fire and wind. But One Thing is eternally numinous and covers heaven and earth. ${ }^{25}$

Jinul continues:

\footnotetext{
(Chinul and Buswell 1983, p. 145), Secrets on Cultivating the Mind (hereafter SCM) in The Korean Approach to Zen. 20 (Chinul and Buswell 1983, p. 163-64), Straight Talk on the True Mind (hereafter STT) in The Korean Approach to Zen. SCM, p. 140. 
It is not your physical body. Furthermore, the four elements which make up the physical body are by nature void; they are like images in a mirror or the moon's reflection in water. How can they be clear and constantly aware, always bright and never obscured. ${ }^{26}$

The Buddha Nature or Mind as actuality is the principle that all human beings have to discover. He says, "In the wisdom of the saint it is no brighter; hidden in the mind of the ordinary man it is no darker". 27

In particular, as Aristotle's form and actuality do, Jinul's Buddha Nature gives the being the telos and power to change. It means that the awakened Buddha Nature precedes gradual cultivation as the telos. Without knowing the direction, in other words, without being awakened to the Buddha Nature, any pursuit of the Truth would be misguided and futile. This idea reflects Aristotle's definition of the end as the full functioning:

For the functioning is the end, and the actuality the functioning; and that is why the name 'actuality' is employed with respect to the functioning and points towards the fulfillment. ${ }^{28}$

The seeker must have the right will and especially the right sense of direction, through "inward illumination", ${ }^{29}$ which reconfigures his purpose of life at the very moment of enlightenment. Therefore, Jinul's actuality can be the full functioning of being, which is the Buddha Nature as the telos. For example, the adulthood is the actuality of a boy. According to Witt, "The boy exists for the sake of an end which is being an actual human being". ${ }^{30}$ What he means by the actual human being is the being, which "is able to perform the array of typical human essential functions that constitute it". ${ }^{31}$ Although the boy has not reached yet adulthood in terms of capabilities, his being is moving toward the internal direction or goal, which is the actuality. Similarly, the awakened monk undertakes his spiritual cultivation with the absolute sense of direction, which is the form and actuality in Aristotle's language.

The Buddha Nature as actuality is also the power or source of change. The power, which cultivates the awakened monk into the full realization or full revelation of Buddhahood is the mind-nature itself. "The mind of void and calm, numinous awareness" is not only the telos or destination toward which the seeker runs with effortless effort and thoughtless thought, but also the power to shape the character of his intellectual and spiritual pursuit and reveal his true nature and identity in the physical, conventional realm, for the bodhisattva vow. Jinul quotes Lin-chi on the Buddha Nature as the source of change:

It is only that formless thing before your eyes, clear and bright of itself, which knows how to expound dharma or listen to dharma. ${ }^{32}$ What is capable of seeing, hearing, moving, and acting has to be your original mind; it is not your physical body. ${ }^{33}$

The medium that translates the Buddha Nature into actuality in Jinul's argument is faith and knowledge. He says, "If you gain some faith and understanding, you will walk hand in hand with the saints of old". ${ }^{34}$ The very moment when we come to have sincere faith in the self-nature is when the ontological transformation for Buddhahood gets activated.

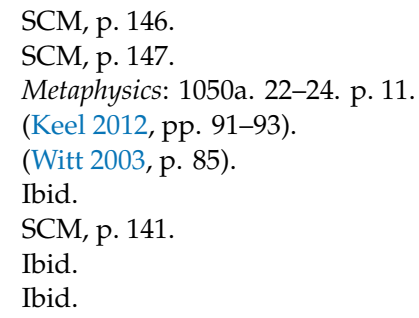




\section{Awakened Monk as Potentiality}

Aristotle's potentiality is formulated by his notion of change. In his Metaphysics XI, he states, "They (potentialities) are all origins of some kind, and are so called in relation to one which is primary, which is an origin of change in something else or in itself qua something else". ${ }^{35}$ Potentiality is the capacity in both quality and quantity to make an object become what it is actually. Laguna defines it as "an inner tendency to reach a natural end, to take on a specific form". ${ }^{36}$ According to Witt, the primary meaning of potentiality is related to "the idea of agent or an active power". ${ }^{37}$ It demands various understandings, depending on how the object is related and interacts with the source of change. Potentiality as agent power can be a rational and non-rational agent. It can also be an active or passive agent. For the degree of the ontological fulfillment, it can be complete or incomplete. Thus, the most basic understanding of potentiality would be whether the source of change/power comes within or without and whether or not the being in question is a natural unity. ${ }^{38}$ Easy examples of the rational and non-rational agent are human beings and non-sentient beings; examples of the agent and passive powers are fire bringing heat to an object and oil being flammable in certain conditions; examples of natural unity are human being, plants, and animals whose ontological change happens to the organism as a whole. Aristotle summarizes variations of potentiality:

It is plain then that there is in a way one capacity of acting and being affected (for something is capable both in that it has a capacity of being acted upon and in that something else can be acted on by it), but in another way they are different. For the one is in the thing affected (for it is because it has a certain origin, and because the matter also is a certain origin, that what is affected is affected, and one thing by another; for what is oily can be burnt while what yields in a certain way can be crushed, and similarly as regards other cases); the other in contrast is in what acts, such as heat and the building craft-the one in what can heat and the other in what can build. That is why, qua naturally unified, nothing is affected by itself; for it is one, and not something else. ${ }^{39}$

This notion of potentiality can support the plausibility of Jinul's second argument of the necessity of gradual cultivation. The major question that the Seon School had against the Gyo School at the time was why the fully awakened monk needs further spiritual cultivation. Although Jinul was related more to the former due to his doctrinal affiliation, he did not think that it was desirable or advisable to completely ignore the practice dimension of awakening because it was an undeniable fact that most Buddhist practitioners, whether awakened or not, would continue to face temptations and challenges of life in the conventional realm and many would fall short of keeping the Buddha Nature. Thus, Jinul had to develop a logical explanation to reconcile sudden awakening and gradual cultivation. The way that Jinul articulates his thought reflects some of the major points of Aristotle's potentiality. Jinul argues that the awakened monk needs to continue to work on his/her spiritual development. How can this claim be compatible with the perfected nature of awakening? The best response would be to reformulate the concept of awakening. Although Jinul did not try to offer a new interpretation of awakening, he did elaborate potential challenges that the awakened monk had to face and how he could sustain the awakening. When talking about the sustainability of awakening in Secrets on Cultivating the Mind, Jinul consistently used conditional clauses. For instance, Jinul says:

This pure, void, and calm mind is that mind of outstanding purity and brilliance of all the Buddhas of the three time period; it is that enlightened nature which is the original source of

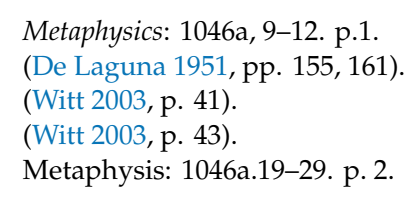


all sentient beings. One who awakens to it and safeguards that awakening will then abide in the unitary, "such" and unmoving liberation. ${ }^{40}$

He continues:

After awakening, you must be constantly on your guard. If deluded thoughts suddenly appear, do not follow after them-reduce them and reduce them again until you reach the unconditioned. Then and only then will your practice reach completion. ${ }^{41}$

Jinul's reservations about the inordinate dependence on sudden enlightenment goes so far even as to confirm the possibility of corruption.

Although the person who has suddenly awakened is the same as the Buddhas, the habitenergies which have built up over many lives as the rooted. The wind ceases, but the waves still surge; the noumenon manifests, but thoughts still invade. ${ }^{42}$

Although Jinul recognizes temptations and the possibility of the degeneration of awakening, he should not mean a qualitative deficiency of the Buddha Nature in the initial awakening. If so, it would undermine the very formative tradition of his Seon Buddhism. As Watson articulates potentiality as "possibility of the actual" rather than of random events, ${ }^{43}$ the full capacity of the Buddhahood should be inherent in the person. To be coherent, Jinul had to keep the position that sudden awakening and gradual cultivation were not two different experiences. He would have argued that they occur in phases in the conventional sense of time but concur in the ultimate dimension. This is the point where Aristotle's notion potentiality becomes suitable to logically explain this paradoxical nature. Sudden awakening and gradual cultivation can be understood temporally. They can be also understood as the quantitative and functional expansion or fulfillment of a single unified substance.

If juxtaposed with the pair of Aristotle's hylomorphism, there are three possible candidates, in general, in Secrets on the Cultivating the Mind, for the notion of potentiality particularly as passive agents. The active agent in Jinul's discussion would be Buddha. He says:

Although we know that a frozen pond is entirely water, the sun's heat is necessary to melt it. Although we awaken to the fact that an ordinary man is Buddha, the power of dharma is necessary to make it permeate our cultivation. When that pond has melted, the water flows freely and can be used for irrigation and cleaning. ${ }^{44}$

Therefore, the first candidate as passive agent is the awakened monk, who has the potential to successfully keep his Buddha Nature; the second is the awakened monk, who has lost the potential to sustain the Buddha Nature; the third is the ordinary people, who lack the potential to actualize the Buddha Nature. What makes them different is the conditioning; how they are prepared as passive agents for the divine transformation or revelation of the Buddha. They can either ontologically flourish or be locked in Manusyaloka. The three previous quotes of Jinul that I have already made in this section explain the first two candidates. The following quotes describe the ordinary people as potentiality not to become Buddha:

Alas, many have broken their ties with the spiritual family of the Buddha in this manner. Since they neither understand for themselves nor believe that others have had an understanding-awakening, when they see someone without spiritual powers they act insolently, ridiculing the sages and insulting the saints. This is really quite pitiful! ${ }^{45}$

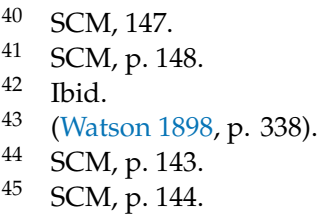


When the ordinary man is deluded, he assumes that the four great elements are his body and the false thoughts are his mind. He does not know that his own nature is the true dharma-body.; he does not know that his own numinous awareness is the true Buddha. He looks for the Buddha outside the mind. ${ }^{46}$

One who is deluded and turns his back on it passes between the six destinies, wandering in samsara for vast numbers of kalpas. ${ }^{47}$

My classification of the seeker as potentiality is meant only for convenience. They all belong to the same category of being. The question is whether they are receptive to the Buddha Nature. What is common is that they all remain as potentialities for the actualization or oblivion of the self-nature.

\section{Cultivation of Buddhahood as Actualization}

When juxtaposed and compared with Aristotle's hylomorphism, Jinul's eclecticism needs to respond to an important and challenging question. How does the ontological unity work in his framework? Since his position maintains that the awakened monks need to continue to work on wholesome qualities, how can the notion of awakening of the Seon school, which presumes the instantaneous perfection of all meritorious qualities, be logical and meaningful? In responding to this question, Jinul focuses on the presence of the practical obstacles in the phenomenal world and repeats the necessity of further spiritual works. Jinul says:

Although he has awakened to the fact that his original nature is no different from that of the Buddhas, the beginningless habit-energies are extremely difficult to remove suddenly and so he must continue to cultivate while relying on this awakening ... he constantly nurtures the sacred embryo. ${ }^{48}$

He continues:

After awakening, you must be constantly on your guard. If deluded thoughts suddenly appear, do not follow after them. ${ }^{49}$

His response does not actually answer the question of why, particularly in Secrets on Cultivating the Mind. The only possible answer would be his denial of the substance of cultivation. Since the evil that the awakened monk has to face is not a substantial entity coming out of his internal desire or will but the illusion from the internal habits, like a plume of smoke after a fire is put out, there is no deficiency in the initial awakening. Jinul explains:

"Thus you eliminate evil, but you eliminate without actually eliminating anything; you cultivate the wholesome, but you cultivate without really cultivating anything either". ${ }^{50}$

To further strengthen his argument for unity, a functional interpretation of Aristotle's actualization would be helpful. According to CAO's functional understanding of actualization, there is no substantial and qualitative difference between potentiality, which is the awakened monk in Jinul's case, and actuality, which is the monk, who has reached the ultimate state of enlightenment. The only difference is quantitative. It means that there is a spectrum or gradation of the functioning of Buddhahood. CAO articulates his functional unity as follows:

\footnotetext{
46 Ibid.

7 SCM, p. 144.

Ibid.

SCM, p. 148.

Ibid.
} 
The ground for the likeness between potentiality and actuality is that both of them belong to one being; in other words, they share one and the same essence and substance and merely differ in degrees. ${ }^{51}$

In other words, actualization is the revelation of two ways of being or different grades of one being rather than an ontological transformation accompanying a substantial and qualitative change. In Secrets on Cultivating the Mind, Jinul nuanced this mode of actualization with the idea of functional unity. Like a human embryo containing the same essence as that of an adult, the awakened monk on cultivation, as potentiality, does not lack any of the Buddha Nature. The awakened monk, like a growing child, needs to continue to get nutrients and strengthen his spiritual muscle with the internal power. Jinul used an example of the growing child:

This (cultivation) process can be compared to the maturation of a child. From the day of its birth, a baby is endowed with all the sense organs just like everyone else, but its strength is not yet fully developed. It is only after many months and years that it will finally become an adult. $^{52}$

If this actualization of Buddhahood is put in CAO's Aristotelian language, the potentiality whose source of change comes within should be free from external hindrances to become actuality because the Buddha Nature is internal. CAO says:

For those things whose source of becoming is internal, if nothing external hinders it and necessarily it will become an actual substance, then this is a potential being. ${ }^{53}$

Jinul says:

If thought moment after thought-moment he continues to train in this manner, does not neglect to maintain his training, and keeps Samadhi and prajna equally balanced, then lust and hatred will naturally fade away and compassion and wisdom will naturally increase in brightness; unwholesome actions will naturally cease and meritorious practices will naturally multiply. ${ }^{54}$

Thus, when Jinul talks about the further cultivation of the awakened monk, he did not think of a change of essence but of a functional growth or fulfillment. Differing from the ordinary people, who willfully reject the dharma, the awakened monk has the full capacity of Buddha. However, the capacity remains potential until it is fully revealed to the phenomenal world through both spiritual and moral expressions. Buswell summarizes the full functioning as the realization of "the noumenal essence, which is the perfect, bright, and self-reliant foundation of the dharmadhatu, and the phenomenal function which manifests objects in the sensory realms in all their diversity". ${ }^{55}$ In other words, both awakening and cultivation experiences are a single event. They are simply spread in the conventional time. But, in the ultimate sense of time, from the viewpoint of the Buddha as form and actuality, they are not separate but unified. Jinul says, "Sudden awakening and gradual cultivation are like the two wheels of a cart: neither one can be missing". ${ }^{56}$

\section{Conclusions: Jinul's Eclecticism as an Enhanced Moral Grounding}

I hope that my utilization of Aristotle's hylomorphism has helped clarify and support the coherence of Jinul's eclecticism on the tension between sudden awakening and gradual cultivation. I have argued

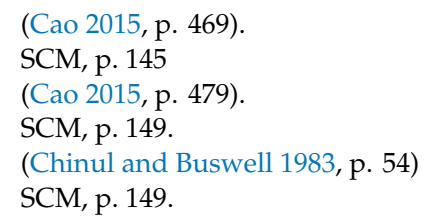


that Aristotle's notion of potentiality and actuality is useful in expounding the logical coherence of the harmony and unity of sudden awakening and gradual cultivation. Although both aspects seem to be separate experiences in the conventional sense of time, they are ontologically united in the ultimate sense of time. The former is the form and essence of the latter. The latter is the revelation of the former in the phenomenal world. They are in sync and unity in the sense that the cultivation is determined for its capacity by the awakening and that the awakening manifests its form through the gradual cultivation leading to the full functioning of the self-nature. The only difference between the one with the initial awakening and the one with the full enlightenment is not qualitative but quantitative in functionality.

In addition to this philosophical discussion, I want to conclude my discussion by highlighting some moral implications of Jinul's eclecticism, which I believe is particularly related to our conference theme: Religious Conflict and Coexistence: the Korean Context and Beyond. Religious tensions and conflicts have been around since the beginning of human history, let alone other types of secular conflicts. The current conflict in Palestine calls to mind the animosity between Israel and Canaan of the old biblical narrative; the history of Islamic Conquest makes many contemporary Christians fear the Muslims as their neighbors; religious extremists armed with fundamentalist theology threaten the modern society based on plurality; and unprecedented Buddhist violence against the Rohingya people in Myanmar challenges our faith in the traditional religion of pacifism.

Although there are numerous reasons for the causes of these conflicts, one of the easiest explanations is the disparity between what religions teach and what their followers actually do. None of the major known world religions promotes division and violence. None of them tolerate discrimination, hatred, and closed-mindedness. Thus, the problem is obviously the lack of integrity. According to Oxford Learner's Dictionary, integrity is a state of whole and not divided. It refers to the moral quality that brings honesty and transparency in our moral thought and action. It ultimately leads to the whole person balanced between moral knowledge and practice. Although intended for spirituality, Jinul's eclecticism offers a strong moral lesson for the negative experiences, which our religious communities have created and suffered. In the last part of Secrets on Cultivating the Mind, Jinul articulates the balance between samadhi and prajña. ${ }^{57}$ Although he talks about the spiritual qualities of calmness and alertness in both the absolute and the relative dimension, a desire for the whole person is nuanced. This thought confirms that sudden awakening and gradual cultivation should be in sync. Both experiences represent the entirety of what it means to be a Buddha. In Buddhist metaphysics and soteriology, being a Buddha is not different in nature from being a whole person particularly in the moral context.

To be more specific, Jinul's emphasis on harmony between the capacities of sudden awakening and gradual cultivation is intended to cultivate the qualities of the two opposite poles of our moral attitude. The former represents calm inner reflection, non-doctrinal spirituality, and the growth of personal spirituality and the latter represents the outer manifestation of the inner qualities, alertness, inquisitive attitude, and engagement in collective effort for the common good. The former is deconstructive in nature and the latter is constructive. To become a Buddha or to fully realize Buddha, one has to get both elements finely tuned. If the former gets extreme, it would fall to self-indulgence. If the latter gets too extreme, it would fall to self-denial. The solution should be to let these two experiences happen simultaneously in practical situations, which I believe is the characteristic of the whole person.

Let me articulate further this moral teaching of Jinul's eclecticism, developed out of my Aristotelian interpretation, with a metaphor of the house. There are two different modes of having moral consciousness. One is to build the house of moral consciousness and the other to deconstruct the house of moral consciousness. The former as the metaphor for gradual cultivation is our capacity, desire, and duty to continue to investigate, expand, and sustain our wisdom to build good moral relations and community and create a divine sense of order and establish norms. We need to constantly experience

57 (Kim 2014, p. 95). 
and engage in the phenomenal world to manifest our true nature by attaining the wisdom of the Buddha whose countless forms need to be discovered and cultivated. It is our active exploration of the truth. In the meantime, the latter as the metaphor for sudden awakening is our capacity to shut down the gate of the outer world and hear the inner voice. It brings things together to absorb the illusory world and ultimately concentrate on the Buddha Nature. It seeks the self-nature within the mind.

Therefore, Jinul's version of hylomorphism of sudden awakening and gradual cultivation naturally leads to the cultivation of the whole person based on three specific virtues: authenticity, transparency, and unity. First, those who have successfully harmonized the initial spiritual enlightenment with the ensuing cultivation should be more authentic than those remaining in either pole in manifesting the wholesome qualities of the Buddha Nature. Since their moral practices come from a deep inner realization of the truth, they are more than followers of moral rules. They themselves feel, learn, and awaken to the dharma penetrating all dimensions of life, including the moral dimension. They themselves become the author of morality by doing what they sincerely believe is true and right. Just as their spiritual work is guided and empowered directly by the self-nature, their action to benefit humanity and the world is genuine and authentic. Their bodhisattva acts are natural and spontaneous. Second, the harmonizer's moral act is consistent and persistent because of the transparency between the inner and outer self. It means that the Buddhist practitioner has a firm foundation for his moral will. He would not be easily swayed by unwholesome internal desires and external pressures and coercion. His moral principles anchored in the spiritual enlightenment of Bodhisattva would not be compromised by any threat or temptation. Third, the unity of awakening and cultivation would perpetuate the positive cycle of the inspiration of the Buddha Mind and its translations into a variety of forms and shapes of compassion; it would ultimately help the seeker with the whole person character be versatile in engaging wisely the constantly changing phenomenal world and its moral contexts. The deconstructive spirit from sudden awakening would help the seeker transcend any type of barrier to make karuna prevail in life. The constructive energy from cultivation would help the seeker find a strong sense of order and direction and constantly engage in new ways to express and explore the endless possibility of the dharma. This whole person character inspired by Jinul's eclecticism should be considered valuable for not only intra-religious but also inter-religious interactions. All religions are on the same journey of finding the Truth but taking different paths and having different experiences. Differences should not be impediments to mutual dialogue but be catalysts to spark intellectual and spiritual curiosity to expand and deepen the understanding of each. I believe that while the idea of gradual cultivation/sanctification would play the role, for any religion, in constructing and sustaining a tradition, sudden awakening/enlightenment/faith would provide a power to transcend any conceptual, spiritual, and geographical barrier. Both elements would bring mature spirituality and developed skills and they would enrich the tradition of each. In particular, when they are harmonized in a spiritual life, a better interaction across different religious communities can be anticipated.

Funding: This research received no external funding.

Conflicts of Interest: The author declares no conflict of interest.

\section{References}

\section{Primary Sources}

Jinul/Chinul. Secrets on Cultivating the Mind (SCM hereafter). pp. 140-59.

Jinul/Chinul. Straight Talk on the True Mind (STT hereafter). pp. 160-90.

\section{Secondary Sources}

Aristotle, and Stephen Makin. 2006. Metaphysics: Book. Oxford: Clarendon Press. Cao, Qingyun. 2015. Aristotle on the Unity of Composite Substance. Frontiers of Philosophy in China 10: 457-73. 
Chinul, and Robert Evans Buswell Jr. 1983. The Korean Approach to Zen: The Collected Works. Honolulu: University of Hawaii Press.

De Laguna, Grace A. 1951. Existence and Potentiality. The Philosophical Review 60: 155-76. [CrossRef]

Durrant, Michael. 1993. Aristotles De Anima in Focus. London and New York: Routledge.

Keel, Hee-Sung. 1989. Salvation According to the Korean Zen Master Chinul and Karl Barth. Buddhist-Christian Studies 9: 13-23. [CrossRef]

Keel, Hee-Sung. 2012. Chinul, the Founder of the Korean Sŏn Tradition. Fremont: Jain Pub. Co.

Kim, Yong-tae. 2014. Global History of Korean Buddhism. Seoul: Dongguk University Press.

Koh, Seung-Hak. 2014. Chinul's Hwaŏm Thought in the Hwaŏmnon Chŏryo. Acta Koreana 17: 163-91. [CrossRef] Mu, Soeng. 1987. Thousand Peaks: Korean Zen-Tradition and Teachers. Berkeley: Parallax Press.

Park, Jin Y. 2005. Zen Language in Our Time: The Case of Pojo Chinuls Huatou Meditation. Philosophy East and West 55: 80-98. [CrossRef]

Shim, Jae-ryong. 1999. Korean Buddhism: Tradition and Transformation. Seoul: Jimoondang Publishing.

Watson, John. 1898. The Metaphysics of Aristotle. The Philosophical Review 7: 337-54. [CrossRef]

Witt, Charlotte. 2003. Ways of Being: Potentiality and Actuality in Aristotles Metaphysics. Ithaca: Cornell University Press.

Yi, Chi-kwan. 1998. Sŏn Thought in Korean Buddhism. Seoul: Dongguk University Press.

(C) 2020 by the author. Licensee MDPI, Basel, Switzerland. This article is an open access article distributed under the terms and conditions of the Creative Commons Attribution (CC BY) license (http://creativecommons.org/licenses/by/4.0/). 